\title{
Dissecting the mechanism of temozolomide resistance and its association with the regulatory roles of intracellular reactive oxygen species in glioblastoma
}

\author{
Chia-Hung Chien' ${ }^{1}$, Wei-Ting Hsueh ${ }^{2}$, Jian-Ying Chuang ${ }^{3,4}$ and Kwang-Yu Chang ${ }^{1,2^{*}}$ (1)
}

\begin{abstract}
Glioblastoma is the most common primary malignant brain tumor that is usually considered fatal even with treatment. This is often a result for tumor to develop resistance. Regarding the standard chemotherapy, the alkylating agent temozolomide is effective in disease control but the recurrence will still occur eventually. The mechanism of the resistance is various, and differs in terms of innate or acquired. To date, aberrations in $\mathrm{O}^{6}$-methylguanine-DNA methyltransferase are the clear factor that determines drug susceptibility. Alterations of the other DNA damage repair genes such as DNA mismatch repair genes are also known to affect the drug effect. Together these genes have roles in the innate resistance, but are not sufficient for explaining the mechanism leading to acquired resistance. Recent identification of specific cellular subsets with features of stem-like cells may have role in this process. The glioma stem-like cells are known for its superior ability in withstanding the drug-induced cytotoxicity, and giving the chance to repopulate the tumor. The mechanism is complicated to administrate cellular protection, such as the enhancing ability against reactive oxygen species and altering energy metabolism, the important steps to survive. In this review, we discuss the possible mechanism for these specific cellular subsets to evade cancer treatment, and the possible impact to the following treatment courses. In addition, we also discuss the possibility that can overcome this obstacle.
\end{abstract}

Keywords: Temozolomide resistance, DNA damage, Glioma stem-like cells, Reactive oxygen species

\section{Background}

Glioblastoma (glioblastoma multiforme, GBM) is the most common primary malignant brain tumor. In the United States, the annual incidence is 5.26 per 100,000 population or 17,000 new diagnoses per year [1]. GBM is the highest grade of glioma by histologic definition, and is the most common and the most aggressive type among them [2]. In the latest version of World Health Organization classification, GBM is categorized based on presence

*Correspondence: kwang2@nhri.edu.tw

${ }^{1}$ National Institute of Cancer Research, National Health Research Institutes, 367 Sheng-Li Road, Tainan 70456, Taiwan

Full list of author information is available at the end of the article or absence of isocitrate dehydrogenase (IDH) mutation [3]. The former usually appears as secondary tumor of the lower grade diseases, and occurs in about the forth to fifth decades of ages. The latter accounts for $90 \%$ of the cases, with most of them occurring in the sixth to seventh decades of ages. A recent study with The Cancer Genome Atlas (TCGA) project had further identified four distinct subgroups for advanced glioma based on the molecular difference: proneural, neural, classical, and mesenchymal [4]. The subclassification differed in genetic expression and the factors to determine the survival advantages [5]. For example, IDH-mutation disease had relatively longer duration of the disease course [3], and thus, recognition of the proneural type that consisted original author(s) and the source, provide a link to the Creative Commons licence, and indicate if changes were made. The images or other third party material in this article are included in the article's Creative Commons licence, unless indicated otherwise in a credit line to the material. If material is not included in the article's Creative Commons licence and your intended use is not permitted by statutory regulation or exceeds the permitted use, you will need to obtain permission directly from the copyright holder. To view a copy of this licence, visit http://creativecommons.org/licenses/by/4.0/. The Creative Commons Public Domain Dedication waiver (http://creativeco mmons.org/publicdomain/zero/1.0/) applies to the data made available in this article, unless otherwise stated in a credit line to the data. 
more of IDH1/2 mutation had its clinical significance [4, 6 , 7]. The aberrations of genes in neural subgroup were more typified of neuron markers [4]. Finally, the classical and the mesenchymal types, which were more related to EGFR and NF1 aberrations, respectively, benefit with more intensive treatment. Altogether, identifying the subgroup characteristics would potentially support clinicians in making the treatment decision [4].

Comparing to the other malignancies, GBM is relatively rare but desperate. The 2-year survival rate is only $26.5 \%$, which has one of the worst outcomes regarding the advancement of latest treatment strategies [8]. Even applying the standard management with surgical intervention is sometimes questionable to gain benefit in disease control. In general, extensive resection is suggested to yield survival advantage, and the relatively conservative stereotactic biopsy is performed only in patients who have inoperable tumors that are located in critical areas [8]. This procedure, however, often accompanies with neurological complications, limiting its extent for tumor eradication. As thus, aggressive management with adjuvant therapy is necessary to maximize the treatment effect. Disappointedly, only limited reagents are considered contributable to disease control. The most widely used anti-tumor agent is radiotherapy and temozolomide (TMZ), a chemotherapy that acts as an alkylating agent to cause lethal DNA damage. The other drugs such as carmustine (BCNU) sponge, alternating electric field therapy (tumor-treating fields device, or TTFields), bevacizumab, cisplatin are active but again, with modest effect in disease control. Novel targeting therapies, such as peptide cancer vaccine against EGFR variant III or immune checkpoint inhibitors, were expected to be successful but ended up with disappointment $[9,10]$. In summary, not much option is available for treatment.

As being the standard systemic treatment agent, TMZ is a second-generation imidazotetrazine lipophilic prodrug. Currently, it is perhaps the most important systemic drug in GBM treatment. It works by hydrolyzing into its active metabolite 5-(3-dimethyl-1-triazenyl) imidazole4-carboxamide. The reactive methyldiazonium ion is then formed to methylation-associated residues in the DNA molecule at $\mathrm{O}^{6}$ - and $\mathrm{N}^{7}$-methylguanine $(\mathrm{MeG})$ or $\mathrm{N}^{7}$-methyladenine (MeA). Regarding $\mathrm{O}^{6}-\mathrm{MeG}$, when DNA mismatch repair (MMR) enzymes attempt to excise the modified nucleotide, they generate single- and double-strand breaks in the DNA that lead to activation of apoptotic pathways if no further repairment is available [11]. The drug has been proven with robust data alone or with radiotherapy in clinical trials and retrospective studies, earning the unequivocal role for treatment of the disease [11-14]. In a clinical trial, patients received standard TMZ/radiotherapy yielded significantly better survival, with $9.8 \%$ of them survived five years after diagnosis [12]. In the TMZ era, the mean survival of glioblastoma in patients age 20-29 could be as long as 31.9 months, highlighting the significant effect of the drug [13]. Those with extremely long survival of more than 4 years are featured with lacking $\mathrm{O}^{6}$-methylguanine-DNA methyltransferase (MGMT, or $\mathrm{O}^{6}$-alkylguanine DNA alkyltransferase) but not the other molecular subclassification [15]. Most of all, the drug is capable of penetrating the blood brain barrier, giving the area under curve of cerebrospinal fluid approximately $20 \%$ of the systemic TMZ exposure [16]. With its superb activity in GBM, the drug has been approved for the treatment with radiation and after for maintenance.

Even with the successful data after introduction of TMZ, the disease, however, remains far from optimal control in clinical aspect. Limited therapeutic efficacy has been a major issue due to eventual failure of the treatment. Despite of the initial response, development of resistance is almost inevitable, with $90 \%$ of patients suffering from early disease recurrence [12]. The remaining course after recurrence is often dismal, and exhibits more deteriorated and resistant nature to the early one. In this article, we review the probable causes leading to the failure of this chemotherapeutic agent. This includes the theories from DNA to cellular levels, and thus, providing an overall understanding of the resistant mechanism against TMZ.

\section{Limitation in theory of $\mathrm{TMZ}$ resistance related to DNA repairing mechanism}

Understanding the resistance mechanism is necessary to help to develop potential strategies against the dilemma. To date, MGMT is the best-known factor leading to resistance of TMZ in GBM [17, 18] (Fig. 1). Inarguably, the factor has been clinically evidenced to contribute the innate tumor resistance against TMZ but not radiotherapy [19]. Presence of MGMT enables cells to remove the alkyl groups from the $\mathrm{O}^{6}$ position of guanine to reverse the cytotoxicity of TMZ [20]. The challenge for this factor to predict treatment outcome, however, is to determine the most reliable and relevant detecting methods. Unfortunately to date, this remained unconfirmed [21]. Because of complicated regulatory mechanism, relying upon promoter research may not be sufficient [22]. This would leave small but certain number of patients to benefit from chemoradiotherapy even with lacking MGMT promoter methylation [23]. In addition, presence of this DNA repairing gene provides only partial explanation for the resistance because about half of patients express the protein and $43-47.5 \%$ of patients have MGMT promoter methylation silenced $[24,25]$. Nevertheless, our understanding of MGMT tends to be helpful in predicting the prognosis of disease. In a large phase III clinical trials 


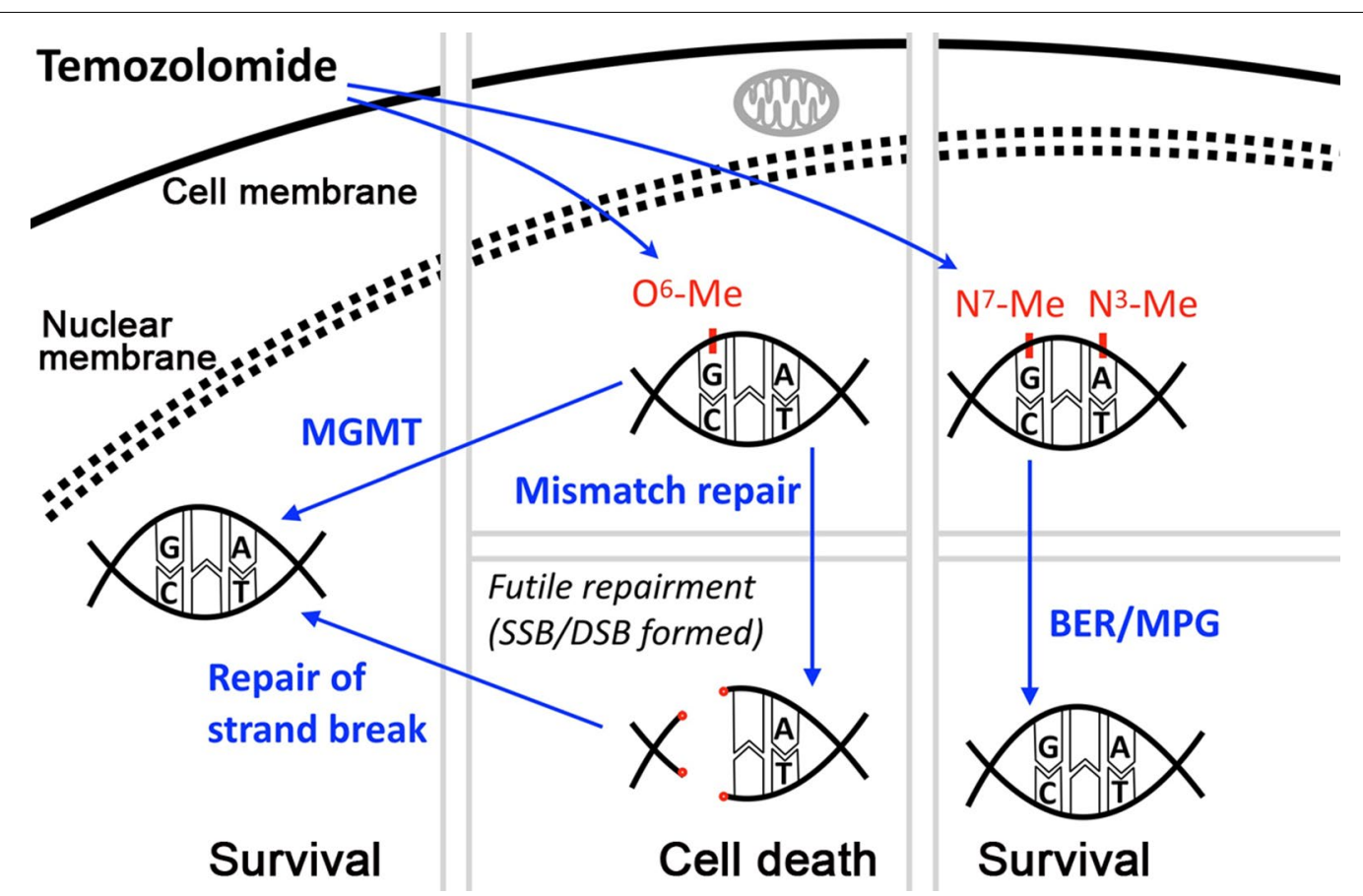

Fig. 1 Schema of classical model of the pharmacology mechanism causing temozolomide (TMZ) resistance. Methylation of $\mathrm{O}^{6}, \mathrm{~N}^{3}$, and $\mathrm{N}^{7}$ in DNA can be modulated by the drug. Repairing response through DDR can cause divergent results. As the notable factor targeting majorly on $\mathrm{O}^{6}$-methylguanine, presence of MGMT leads to salvage for the cells to survive, and thus, will have negative impact to drug susceptibility in terms of the drug effect. Without adequate rescuing action, futile repairment will lead to single- or double-strand break, leading to associated reaction causing cell death. Me methylation, SSB single-strand break, DSB double-strand break, BER base excision repair, MPG N-methylpurine DNA glycosylase

with 833 newly diagnosed patients receiving standard or dose-dense TMZ, stratification with the status of the MGMT promoter identified improved survival data in methylated groups [26]. Moreover, the role for the gene status to guide application of TMZ is in suggestive. Two phase III trials, one in general and the other in elderly populations, suggested effectiveness of adding TMZ to radiotherapy in patients with methylated MGMT disease $[12,27]$. To date, MGMT is the best known but not the only determinant in TMZ susceptibility.

The general understanding of DNA repairing mechanism, derived from DNA single-strand break or double-strand break, suggests activation of the other DNA damage repair (DDR) genes may also have roles, especially in lab research, but requires more evidences to elucidate [28]. As being the key factor to generate TMZ toxicity, the deficiency in MMR can have association with the resistance (Fig. 1). In a TCGA study, mutation of MSH6, a DNA mismatch repair gene, in post-treatment samples were identified to be associated with TMZ resistance [29]. In addition, this may have severe consequence by accelerating mutagenesis in resistant clones that could promote the neoplastic progression [30]. There was challenge in this theory, however, that only
$3 \%$ of 70 clinical samples showed single loci microsatellite instability (MSI) while no sample was with high MSI [31]. The rarity of alterations in promoter methylation was also confirmed by Felsberg, et al., showing only 9 in 80 patients and none in 43 patients had altered methylation in MGMT and in DNA mismatch repair genes including MLH1, MSH2, MSH6, and PMS2, respectively [32]. On the other hand, the authors found decreased expression of these MMR proteins in the recurrent tissue. Though controversy remains for each single factor to determine TMZ susceptibility, the DDRs associated with the modulation by $\mathrm{TMZ}$ in $\mathrm{O}^{6}-\mathrm{MeG}$ are suggested to have net impact in the resistance. As thus, recent studies put together MGMT, MMR, nucleotide excision repair (NER), homologous recombination (HR) for prediction of the drug response [33]. Finally, despite of fewer roles in $\mathrm{N}^{7}-\mathrm{MeG}$ to relate with TMZ drug cytotoxicity, cells proficient at repairing with base excision repair (BER) enzyme, the major targeting repairing protein, was also reported to cause resistance [2] (Fig. 1).

Setting up histological criteria based on the aforementioned DDRs is seemingly practicable and can contribute to personalized algorithm in guiding patients to receive the most appropriate treatment [23]. However, this only 
applies to prediction of drug response related to innate resistance, and is not avoidable for eventual treatment failure. In addition, the theory is only applicable of cellular level and ignores the impact of heterogeneity and the microenvironment that also compose for the tumor [34]. Regarding the complexity, it is doubtful that DDRs are fully responsible for all the mechanism in resistance. This is especially of noted in terms of acquired resistance, which the roles of DDRs remain ambiguous. Unlike the findings in rodent models [17], studies to date on whether anti-cancer therapies are responsible for inducing MGMT in humans have been inconclusive [35]. Much question remains regarding of cells to acquire resistance, suggesting more complicated and multi-factorial mechanisms.

\section{Dissecting the role of cancer stem-like cells in TMZ resistant mechanism}

Limitation in DDR to fully explain the resistant mechanism gives rise to other theories such as cancer stem-like cells (CSCs) model, which represents specific subsets in the heterogeneous tumors accountable for acquiring treatment resistance and turning into more aggressive form [36]. These are characterized as the cells possessing self-renewal and multipotent properties [37]. The hypothesis suggests the cells possessing more intractable and resistant features, and is responsible for the disease recurrence after treatment [36]. In prostate cancer, for instance, enrichment of the CSC subpopulation after recurrence was characterized as lacking expression of androgen receptors and prostate specific antigen, indicating it to be no longer relying on hormone [38]. In GBM, this was supported by glioma cells carrying the stemness gene Nestin that could propagate the recurrence of GBM following TMZ treatment [39]. The specific subsets empowered with the features of stem-like cells were evidenced to take advantage in withstanding the treatment toxicity. The leukemia study showed that tumor specific treatment promotes outgrowth of the minor subsets with resistant power, with the initiating properties crucial in reserving the cells [40]. In a GBM study, tracing of the individual subpopulations showed their capability of phenotype adjustment, with outgrowth of specific ones determined by the adaptation speed to stress [41]. The theory remains worthwhile to define the phenomenon regarding explanation of the acquisition model in drug resistance.

Nevertheless, the theory often comes with controversy [42]. Inconsistent conclusion is often made between studies to studies because of the over-simplified methods for detection. For example, biomarker study without functional concerns may result in misleading recognition of the "CSC" subsets. Notably, application of CD133 as a universal phenotype marker in glioblastoma could be irrelevant [43]. This may be related to emergent understanding of the theory to have more commonality between clonal evolutions and CSC models [44], highlighting plasticity and dynamic of CSC features to adapt themselves against external microenvironment [45]. In other word, even the cells carrying the stemness features are also very dynamic and heterogenic in expression and function [46], and thus, application of single biomarker as representative of this specific group is insufficient [47]. In fact, in colon cancer, there were discordance between the stem cell-like features and the phenotype markers [48]. Regarding the complexity, comprehensive functional analysis to characterize the cells is hence mandatory [37], including functional characteristics such as substantial self-renewal, persistent proliferation, and tumor initiation. Specific methods, such as serial transplantation in a xenograft assay for self-renewal test, are applied to identify their ability [49]. Importantly, it is worth to note that cell lines often diminish or lose the ability of initiation and maintaining the cancer during long-term culture process. Even with keeping the stem-cell properties, the long-established cell lines were found to lose the nature of the disease such as incapable to form neuronal differentiation [50]. The relevant researches of these features thereby depends more on patient-derived xenograft tissue, which has the advantage in maintaining their properties because of avoiding differentiation by long-term culturing with serum-containing medium [50]. To summarize, functional studies of CSCs in cell lines can provide validation for stem-cell features [51].

Conventionally, drug resistance of CSCs is caused by abundant ATP-binding cassette $(\mathrm{ABC})$ transporters expression in the cells. These proteins enable the cells to pump out drugs before intracellular damage occurs, allowing them to withstand the drug toxicity. The associations of the $\mathrm{ABC}$ transporters and CSCs are close, providing basic theory for "side population (SP) assay" to identify them [52]. This methodology somehow has limitation because certain normal tissue expresses the protein, and some CSC populations do not express it [53]. In regard with brain tissue, the $A B C$ transporters is characterized between the barriers of blood and brain or blood and cerebrospinal fluid barrier, and is responsible for poor penetration of the drug [54, 55]. The fact turns to bring troublesome for applying SP assay to identify the CSC subpopulation in GBM since the barriers is often involved in the disease [56]. Of note, the specific cells isolated by SP assays in GBM cell lines and the primary tumor cells was not associated with cell capability of the self-renewal phenotype [57]. Further analysis of patient-derived xenograft revealed cells with SP identity was composed of the brain endothelial cells and was 
non-tumorigenesis [58]. These concluded the $\mathrm{ABC}$ transporters may not or are only partly involved in the resistant mechanism of GBM CSCs.

\section{Superior regulation of reactive oxygen species (ROS) in glioma stem-Like cells (GSCs)}

Adaption of tumor cells is critical for their facing constantly fluctuating stress from internal environment or from anti-tumor treatment. With regard to TMZ, the drug itself and its analog TMZ-perillyl alcohol conjugate, were shown to up-regulate ROS production in GBM cells and non-small cell lung cancer cells, respectively $[59,60]$. ROS is paradoxically critical both in the promotion of cancer progression and the induction of a detrimental cytotoxic response [61]. In fact, the main components of ROS include superoxide $\left(\mathrm{O}_{2}{ }^{-}\right)$, hydrogen peroxide $\left(\mathrm{H}_{2} \mathrm{O}_{2}\right)$, and hydroxyl radical $\left({ }^{\circ} \mathrm{OH}\right)$ [62]. Presence of superoxide is essential for cells to potentiate receptor tyrosine kinases (RTKs) such as EGFR and VEGFR [63, 64], in which the signaling aberrations are often related to the carcinogenesis of GBM [65]. As thus, several reports have shown that inhibition of ROS with $\mathrm{N}$-acetylcysteine or ascorbic acid to decrease the risk of the disease [66-69]. On the contrary, unlike the physiology one, ROS generated by the treatment was through increase of excessive superoxide to induce the DNA damage response. Therefore, alleviation of ROS may mitigate the drug response, which interferes tumor control [70]. Multiple factors can be involved in this regulation. Nuclear factor-erythroid-2-related factor 2 (Nrf-2) is the most well-known regulator [71, 72]. In regard with TMZ, specific protein 1 ( $\mathrm{Sp} 1$ ) was also triggered by ROS [73, 74], and was known to be a factor in the tolerance of the treatment-induced ROS [75]. This was through modulation of a ROS scavenging protein, superoxide dismutase (SOD) 2, and hence altered the regulation of oxidative stress and energy metabolism [76]. As thus, it is not surprising that certain cells possess an enhanced activity of antioxidant to tightly regulate ROS levels, thus maintaining viability and avoiding oxidative stress from anticancer therapy.

Cell-based regulation of ROS is critical. Extrinsic sourced and endogenously generated reactive oxidants are continually infused to cells by balancing of metabolized oxygen. This is a physiologically regulated process, with deregulation leading to oxidative stress and pathologic consequence of cells [77]. Organelles such as mitochondria and endoplasmic reticulum, as well as enzymes including NADPH oxidases, xanthine oxidase, nitric oxide synthase and peroxisome, generate ROS. This leads to production of superoxide, which itself is only limited in impact. With the mid-product, secondary radical species can be generated after its variable reactions that yield multiple ROS and reactive nitrogen species, for example, hydrogen peroxide $\left(\mathrm{H}_{2} \mathrm{O}_{2}\right)$ and peroxynitrite $\left(\mathrm{ONOO}^{-}\right)$ [78]. Superoxide and its derivatives, especially $\mathrm{H}_{2} \mathrm{O}_{2}$, have crucial roles in promoting cellular proliferation, migration, and pathogen defensive mechanism [79] (Fig. 2). On the other hand, accumulation of the species can bring stress to cells. As thus, strict regulation of the product is essential to avoid oxidative damage from stress overload and for the maintenance of cell viability [80].

As of the regulatory mechanism, the ROS scavengers are the mainstay for the reaction. The protein family was composed of multiple enzymes including SODs, catalase, and glutathione peroxidase (GPx), with each having different role in the different stages required to convert superoxide into water and oxygen [81]. In regard with the first step of this reaction, three classes of dismutases are involved and distributed in different area of cells. SOD1 is spread in cytoplasm in majority to regulate the superoxide from NADPH oxidase reaction and cytochrome p450-monooxygenases in the endoplasmic reticulum. SOD2 is located in mitochondria, which the electron transport chain of mitochondria is the main sources to generate electron for superoxide formation. There is another dismutase, SOD3, located in the extracellular space, having various important roles in pathophysiology such as hypertension [82]. The proteins possess different catalytic metal ions, with SOD1 and SOD3 through $\mathrm{Cu} /$ $\mathrm{Zn}$ and SOD2 through $\mathrm{Mn}$. By this reaction, superoxide is catalyzed to $\mathrm{H}_{2} \mathrm{O}_{2}$ and oxygen. The process continues with the hydrogen peroxide reduced to $\mathrm{H}_{2} \mathrm{O}$ and $\mathrm{O}_{2}$. This will need the involvement of catalase or GPx (Fig. 2).

Regarding the heterogeneity by cell-to-cell bases in tumor tissue, it is not surprising some cells have superior ability in regulating ROS. As aforementioned, the CSC subsets are with altered cellular features. Since external factors such as hypoxia plays crucial role in contribution of resistance in tumor tissue, the specific subsets can take advantage from the extreme condition [83]. GSCs, the CSCs specified in glioma, are preferably concentrated by perivascular, hypoxic, invasive niches regarding with the microenvironments [84]. The microenvironment was suggested to have role in treatment resistance, possibly through enrichment of GSCs [85, 86]. In neural stem cells, presence of hypoxia promotes cell differentiation and proliferation, suggesting how the external factor impacts [87]. In presence of hypoxia, the stemness features in GSC may lead to dominant expression of MGMT by increasing function of hypoxia inducible factors [88-90]. In addition, as being one of the stem cell factors, the polycomb group protein Bmi-1 was shown to have a crucial role in the GSCs homeostasis in response of ROS stress [91]. The activation of this factor is associated with radioresistance 


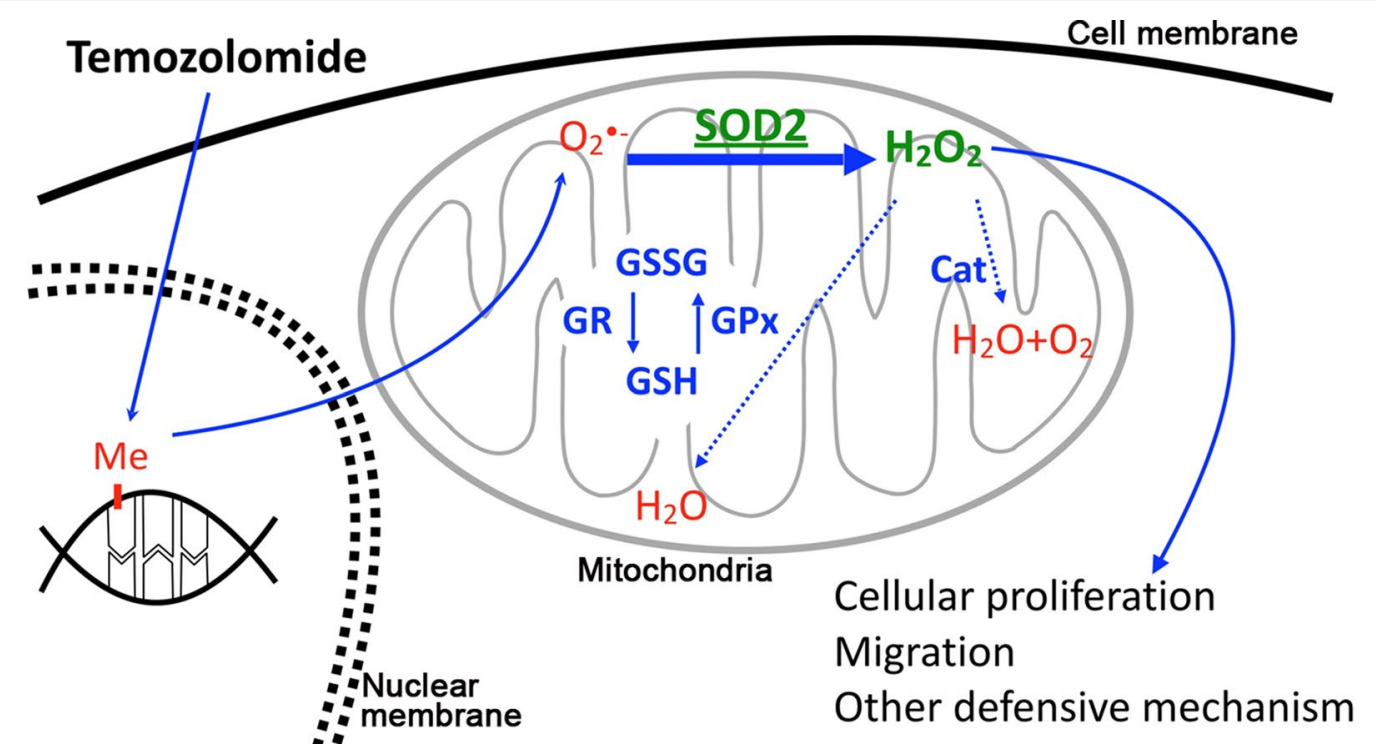

Fig. 2 Schema of mechanism with involvement of ROS-related factors to take place in mitochondria in temozolomide (TMZ) resistance. Toxicity of TMZ induces excessive superoxide generation which requires activation of ROS scavengers to detoxify. Accumulation of ROS, on the other hand, promotes tumorigenesis. The two-handed sword effect of ROS induced by TMZ can end up in sparing the intractable cells that have superior regulatory ability. The remaining cells that survive chemotherapy will thus thaw and replace the vulnerable counterparts. Cat catalase, GR glutathione reductase, GSH glutathione, GSSG glutathione disulfide

through the recruitment of DDRs [92]. Supportively, in a study by Garnier, et al., the appearance of DDRs was suggested to be a result of stochastic and unpredictable development from divergent evolution based on GSCs [93]. It is thus interesting that aberration of genetic repairing factors is related to CSCs and ROS in terms of resistance in GBM.

In cellular level, mitochondria are one of the most important organelles in adjusting against the external stress. It is not surprising for CSCs to have invigorated mitochondrial dynamics that offers advantage in withstanding the tough environment [94]. Mitochondria contribute to cancer in multiple aspects and seemingly have roles in progression and chemoresistance [95, 96]. Especially for treatment that works through generating excessive ROS such as TMZ treatment with or without radiotherapy, this would be of concern because the majority of ROS regulation in the cells takes place in mitochondria. In terms of the CSCs, the appearance of mitochondria differs from the differentiated cells by demonstrating underdeveloped structure such as more sparse and fragment with limited cristae. The CSCs also appears with less mitochondrial DNA. This is in reflex of cells to process high glycolytic flux and keeping itself in lower ROS, which may functionally support the self-renewal ability and the genome maintenance [94, 97]. With the acquisition of chemoresistance, a study showed that mitochondria responded to TMZ genotoxic stress with a major contribution from alternation of cytochrome c oxidase [98].

To maintain in a lowered ROS and possibly to withstand the cytotoxicity of cancer treatment, altered metabolic reprogramming by mitochondrial control in cancer may play a critical role $[96,99]$. Many cancer cells rely on glycolysis over oxidative phosphorylation [100]. This is known as Warburg effect, which allows cancer cells to utilize the byproduct of glycolytic flux for synthesis of fatty acids, amino acids, and nucleotides. In addition, the production of lactate can be released to microenvironment and to feed adjacent oxidative cancer cells and to promote angiogenesis [101]. For the stemness-featured cells, glycolysis utilization is even more favored comparing to the differentiated cells [102]. Glycolysis reduces ROS production that can be destructive to DNA, keeping longevity of genome maintenance. More importantly, the derivations of cytosolic acetyl-CoA are critical for these cells to maintain histone acetylation and pluripotency [103]. With the feature, it is not surprising for CSCs, which possess superior regulation to maintain in lower ROS, to evade the effect of the treatment that delivers excessive ROS to the cells. Altogether, the theory highlights how the microenvironment and the anti-cancer therapy impact the CSC features to take advantage. In head and neck cancer cells, the specific subsets exhibited superior superoxide adjusting ability to withstand cisplatin treatment, which was also known to induce excessive 
ROS [104]. In GBM, we suggested that acquisition of TMZ resistance was a result of enriched cells with stem cell properties with enhanced SOD2 [105]. Finally, with the advanced methodology such as tracing system in the cells expressing stemness features, we expect the role of the specific subsets in drug resistance will be revealed in the future [106].

\section{Clinical implication regarding GSCs and TMZ resistance}

As reviewed above, utilization of ROS and the altered mitochondria functioning in CSCs are critical for these specific subsets to survive and thrive from TMZ toxicity. This may also affect the effect of re-applying the current treatment or changing to the next-line treatment since many of the current therapy relied on ROS induction. For example, the ionizing radiation achieves tumor control by inducing oxidizing events that is harmful for DNA. Multiple chemotherapy agents achieve to control the disease by association with eliciting ROS reaction [107]. It was noted that induction of oxidative stress enhanced the effect of $\mathrm{BCNU}$ while presence of anti-oxidant alleviates the effect $[71,108]$. Though not the standard reagent, the effect of widely-used cisplatin was also inferior in low-ROS exhibiting CSCs [104]. Recently approved TTFields contributes to the disease control by low-intensity electric fields that blocks cell division and interferes with organelle assembly [109]. The fact that sorafenib enhanced the effect of TTFields through increasing ROS to promote apoptosis also brings to worrisome in crossresistance [110]. In general, replacement of the tumor cells that has superior capability in dealing with ROS can be troublesome in salvage treatment with the other anti-tumor strategies, which is a characteristic for the acquired resistance.

Strategies should be made to avoid the cross-resistance. Bevacizumab, which is an approved targeting therapy against VEGF, can be chosen with less impact in ROS. The other methods are active studying for tumor markers associated with anti-oxidant factors, such as Nrf-2 or SOD2. Direct modulation of ROS may also avoid the resistance or enhance the treatment [111]. Downregulation of glutathione reductase can resensitize the resistant GBM cells to TMZ or cisplatin [112]. In our previous studies, application of Sp1 or SOD inhibitor could down-regulate TMZ-induced ROS and promoted the cytotoxicity of resistant cells [75]. Metabolism of glycolysis is served as new target [113]. In addition, recent understanding of autophagy in protecting the cells from cytotoxicity also reveals the association with ROS and mitochondrial alteration [114-117]. As thus, application of chloroquine treatment to block autophagy can induce the increased production of intracellular or mitochondrial ROS $[118,119]$. This will also cause accumulation of damaged mitochondria or oxidative stress $[120,121]$. Finally, the plasticity model for CSC suggests epigenomic regulation crucial for the features to convert in cells [122]. With the enthusiasm of CSC studies recently, targeting the relative factors is on the way for clinical trials [123]. As thus, specific strategies such as applying a histone deacetylases inhibitor, suberoylanilide hydroxamic acid, could be studied for the potential strategies in reducing or overcoming the resistance [124].

\section{Conclusions}

Limited breakthrough has been achieved in GBM treatment in the past few years. Before the major leap to happen, inspection of the tumor biology is potentially contributable in optimizing treatment to improve the disease outcome and in developing novel therapeutic strategies. Regarding the underlying resistant mechanism of TMZ, rationales were suggested to combine the firstline drug along with simultaneous suppression over the higher protection mechanisms of the stem-like cells to seek for opportunity to enhance the drug efficacy. This can possibly be achieved by modulating selective factors related to these specific subsets, such as enhancement of antioxidant enzymes, energy metabolism, and adaptation in the microenvironment. Though the inhibition may not be straightforward, the rationale suggests a potential framework to benefit cancer treatment.

Abbreviations.

GBM: glioblastoma multiforme; TMZ: temozolomide; BCNU: carmustine; TTFields: tumor-treating fields device; IDH: isocitrate dehydrogenase; Nrf-2: nuclear factor-erythroid-2-related factor 2; Sp1: specific protein 1; SOD2: superoxide dismutase 2; ROS: reactive oxygen species; $\mathrm{H}_{2} \mathrm{O}_{2}$ : hydrogen peroxide; GPx: glutathione peroxidase, MGMT: $\mathrm{O}^{6}$-methylguanine-DNA methyltransferase; TCGA: The Cancer Genome Atlas; MSI: microsatellite instability; CSC: cancer stem-like cell; GSC: glioma stem-like cell; SP: side population; $A B C$ : ATP-binding cassette; DDR: DNA damage repair; NER: nucleotide excision repair; HR: homologous recombination; BER: base excision repair; RTK: receptor tyrosine kinase; EGFR: epidermal growth factor receptor; VEGFR: vascular endothelial growth factor receptor.

\section{Acknowledgements \\ Not applicable.}

\section{Authors' contributions}

CHC, WTH, JYC and KYC wrote the manuscript and KYC supervised the final version. All authors read and approved the final manuscript.

\section{Funding}

This work was supported by grants from the Ministry of Science and Technology, Taiwan (MOST 109-2013-B-400-036) and National Health Research Institutes, Taiwan (CA-109-PP-08). 
Availability of data and materials

Not applicable.

\section{Declarations}

Ethics approval and consent to participate

Not applicable.

\section{Consent for publication}

Not applicable.

\section{Competing interests}

The authors have no competing interests.

\section{Author details}

${ }^{1}$ National Institute of Cancer Research, National Health Research Institutes, 367 Sheng-Li Road, Tainan 70456, Taiwan. ${ }^{2}$ Department of Oncology, College of Medicine, National Cheng Kung University Hospital, National Cheng Kung University, Tainan, Taiwan. ${ }^{3}$ Center for Neurotrauma and Neuroregeneration, Taipei Medical University, Taipei, Taiwan. ${ }^{4}$ The Ph.D. Program for Neural Regenerative Medicine, Taipei Medical University, Taipei, Taiwan.

Received: 13 November 2020 Accepted: 1 March 2021

Published online: 08 March 2021

\section{References}

1. Omuro A, DeAngelis LM. Glioblastoma and other malignant gliomas: a clinical review. JAMA. 2013;310:1842-50.

2. Agnihotri S, Gajadhar AS, Ternamian C, Gorlia T, Diefes KL, Mischel PS, et al. Alkylpurine-DNA-N-glycosylase confers resistance to temozolomide in xenograft models of glioblastoma multiforme and is associated with poor survival in patients. J Clin Invest. 2012;122:253-66.

3. Louis DN, Perry A, Reifenberger G, Deimling AV, Figarella-Branger D, Cavenee WK, et al. The 2016 World Health Organization Classification of Tumors of the Central Nervous System: a summary. Acta Neuropathol. 2016;131:803-20.

4. Verhaak RG, Hoadley KA, Purdom E, Wang V, Qi Y, Wilkerson MD, et al. Integrated genomic analysis identifies clinically relevant subtypes of glioblastoma characterized by abnormalities in PDGFRA, IDH1, EGFR, and NF1. Cancer Cell. 2010;17:98-110.

5. Brennan CW, Verhaak RG, McKenna A, Campos B, Noushmehr H, Salama SR, et al. The somatic genomic landscape of glioblastoma. Cell. 2013;155:462-77.

6. Phillips HS, Kharbanda S, Chen R, Forrest WF, Soriano RH, Wu TD, et al. Molecular subclasses of high-grade glioma predict prognosis, delineate a pattern of disease progression, and resemble stages in neurogenesis. Cancer cell. 2006;9:157-73.

7. Yan H, Parsons DW, Jin G, McLendon R, Rasheed BA, Yuan W, et al. IDH1 and IDH2 mutations in gliomas. N Engl J Med. 2009;360:765-73.

8. Wen PY, Kesari S. Malignant gliomas in adults. N Engl J Med. 2008:359:492-507.

9. Weller M, Butowski N, Tran DD, Recht LD, Lim M, Hirte H, et al. Rindopepimut with temozolomide for patients with newly diagnosed, EGFRvIll-expressing glioblastoma (ACT IV): a randomised, double-blind, international phase 3 trial. Lancet Oncol. 2017;18:1373-85.

10. Filley AC, Henriquez M, Dey M. Recurrent glioma clinical trial, CheckMate-143: the game is not over yet. Oncotarget. 2017;8:91779-94.

11. Koukourakis GV, Kouloulias V, Zacharias G, Papadimitriou C, Pantelakos $P$, Maravelis $G$, et al. Temozolomide with radiation therapy in high grade brain gliomas: pharmaceuticals considerations and efficacy; a review article. Molecules. 2009;14:1561-77.

12. Stupp R, Hegi ME, Mason WP, van den Bent MJ, Taphoorn MJB, Janzer $R C$, et al. Effects of radiotherapy with concomitant and adjuvant temozolomide versus radiotherapy alone on survival in glioblastoma in a randomised phase III study: 5-year analysis of the EORTC-NCIC trial. Lancet Oncol. 2009;10:459-66.

13. Johnson DR, O'Neill BP. Glioblastoma survival in the United States before and during the temozolomide era. J Neurooncol. 2012;107:359-64
14. Stupp R, Mason WP, van den Bent MJ, Weller M, Fisher B, Taphoorn MJB, et al. Radiotherapy plus concomitant and adjuvant temozolomide for glioblastoma. N Engl J Med. 2005;352:987-96.

15. Gerber NK, Goenka A, Turcan S, Reyngold M, Makarov V, Kannan K, et al. Transcriptional diversity of long-term glioblastoma survivors. Neuro Oncol. 2014;16:1186-95.

16. Ostermann S, Csajka C, Buclin T, Leyvraz S, Lejeune F, Decosterd LA, et al. Plasma and cerebrospinal fluid population pharmacokinetics of temozolomide in malignant glioma patients. Clin Cancer Res. 2004;10:3728-36

17. Kitange GJ, Carlson BL, Schroeder MA, Grogan PT, Lamont JD, Decker PA, et al. Induction of MGMT expression is associated with temozolomide resistance in glioblastoma xenografts. Neuro Oncol. 2009;11:281-91.

18. Munoz JL, Rodriguez-Cruz V, Greco SJ, Nagula V, Scotto KW, Rameshwar P. Temozolomide induces the production of epidermal growth factor to regulate MDR1 expression in glioblastoma cells. Mol Cancer Ther. 2014;13:2399-411.

19. Wick W, Platten M, Meisner C, Felsberg J, Tabatabai G, Simon M, et al. Temozolomide chemotherapy alone versus radiotherapy alone for malignant astrocytoma in the elderly: the NOA-08 randomised, phase 3 trial. Lancet Oncol. 2012;13:707-15.

20. Pegg AE, Byers TL. Repair of DNA containing O6-alkylguanine. FASEB J. 1992;6:2302-10.

21. Christians A, Hartmann C, Benner A, Meyer J, von Deimling A, Weller M, et al. Prognostic value of three different methods of MGMT promoter methylation analysis in a prospective trial on newly diagnosed glioblastoma. PLoS One. 2012;7:e33449.

22. Erasimus H, Gobin M, Niclou S, Van Dyck E. DNA repair mechanisms and their clinical impact in glioblastoma. Mutat Res Rev Mutat Res. 2016:769:19-35.

23. Wick W, Weller M, van den Bent M, Sanson M, Weiler M, von Deimling A, et al. MGMT testing-the challenges for biomarker-based glioma treatment. Nat Rev Neurol. 2014;10:372-85.

24. Costa BM, Caeiro C, Guimaraes I, Martinho O, Jaraquemada T, Augusto I, et al. Prognostic value of MGMT promoter methylation in glioblastoma patients treated with temozolomide-based chemoradiation: a Portuquese multicentre study. Oncol Rep. 2010;23:1655-62.

25. Perry JR, Belanger K, Mason WP, Fulton D, Kavan P, Easaw J, et al. Phase II trial of continuous dose-intense temozolomide in recurrent malignant glioma: RESCUE study. J Clin Oncol. 2010;28:2051-7.

26. Gilbert MR, Wang M, Aldape KD, Stupp R, Hegi ME, Jaeckle KA, et al. Dose-dense temozolomide for newly diagnosed glioblastoma: a randomized phase III clinical trial. J Clin Oncol. 2013;31:4085-91.

27. Perry JR, Laperriere N, O'Callaghan CJ, Brandes AA, Menten J, Phillips C, et al. Short-course radiation plus temozolomide in elderly patients with glioblastoma. N Engl J Med. 2017;376:1027-37.

28. Yoshimoto K, Mizoguchi M, Hata N, Murata H, Hatae R, Amano T, et al. Complex DNA repair pathways as possible therapeutic targets to overcome temozolomide resistance in glioblastoma. Front Oncol. 2012;2:186.

29. Yip S, Miao J, Cahill DP, lafrate AJ, Aldape K, Nutt CL, et al. MSH6 mutations arise in glioblastomas during temozolomide therapy and mediate temozolomide resistance. Clin Cancer Res. 2009;15:4622-9.

30. Hunter C, Smith R, Cahill DP, Stephens P, Stevens C, Teague J, et al. A hypermutation phenotype and somatic MSH6 mutations in recurrent human malignant gliomas after alkylator chemotherapy. Cancer Res. 2006;66:3987-91.

31. Maxwell JA, Johnson SP, McLendon RE, Lister DW, Horne KS, Rasheed A, et al. Mismatch repair deficiency does not mediate clinical resistance to temozolomide in malignant glioma. Clin Cancer Res. 2008;14:4859-68.

32. Felsberg J, Thon N, Eigenbrod S, Hentschel B, Sabel MC, Westphal M, et al. Promoter methylation and expression of MGMT and the DNA mismatch repair genes MLH1, MSH2, MSH6 and PMS2 in paired primary and recurrent glioblastomas. Int J Cancer. 2011;129:659-70.

33. Nagel ZD, Kitange GJ, Gupta SK, Joughin BA, Chaim IA, Mazzucato P, et al. DNA repair capacity in multiple pathways predicts chemoresistance in glioblastoma multiforme. Cancer Res. 2017;77:198-206.

34. Broekman ML, Maas SLN, Abels ER, Mempel TR, Krichevsky AM, Breakefield XO. Multidimensional communication in the microenvirons of glioblastoma. Nat Rev Neurol. 2018;14:482-95. 
35. Christmann M, Kaina B. Transcriptional regulation of human DNA repair genes following genotoxic stress: trigger mechanisms, inducible responses and genotoxic adaptation. Nucleic Acids Res. 2013:41:8403-20.

36. Vidal SJ, Rodriguez-Bravo V, Galsky M, Cordon-Cardo C, DomingoDomenech J. Targeting cancer stem cells to suppress acquired chemotherapy resistance. Oncogene. 2014;33:4451-63.

37. Lathia JD, Mack SC, Mulkearns-Hubert EE, Valentim CL, Rich JN. Cancer stem cells in glioblastoma. Genes Dev. 2015;29:1203-17.

38. Zhang W, Meng Y, Liu N, Wen XF, Yang T. Insights into chemoresistance of prostate cancer. Int J Biol Sci. 2015;11:1160-70.

39. Chen J, Li Y, Yu TS, McKay RM, Burns DK, Kernie SG, et al. A restricted cell population propagates glioblastoma growth after chemotherapy. Nature. 2012:488:522-6.

40. Notta F, Mullighan CG, Wang JC, Poeppl A, Doulatov S, Phillips LA, et al. Evolution of human BCR-ABL1 lymphoblastic leukaemia-initiating cells. Nature. 2011;469:362-7.

41. Dirkse A, Golebiewska A, Buder T, Nazarov PV, Muller A, Poovathingal S, et al. Stem cell-associated heterogeneity in glioblastoma results from intrinsic tumor plasticity shaped by the microenvironment. Nat Commun. 2019;10:1787.

42. Beier D, Schulz JB, Beier CP. Chemoresistance of glioblastoma cancer stem cells-much more complex than expected. Mol Cancer. 2011:10:128.

43. Safa AR, Saadatzadeh MR, Cohen-Gadol AA, Pollok KE, Bijangi-Vishehsaraei K. Glioblastoma stem cells (GSCs) epigenetic plasticity and interconversion between differentiated non-GSCs and GSCs. Genes Dis. 2015;2:152-63.

44. Visvader JE, Lindeman GJ. Cancer stem cells in solid tumours: accumulating evidence and unresolved questions. Nat Rev Cancer. 2008:8:755-68

45. Chen W, Dong J, Haiech J, Kilhoffer MC, Zeniou M. Cancer stem cell quiescence and plasticity as major challenges in cancer therapy. Stem Cells Int. 2016;2016:1740936.

46. Meacham CE, Morrison SJ. Tumour heterogeneity and cancer cell plasticity. Nature. 2013;501:328-37.

47. Feng JM, Miao ZH, Jiang Y, Chen Y, Li JX, Tong $L$, et al. Characterization of the conversion between CD133 + and CD133-cells in colon cancer SW620 cell line. Cancer Biol Ther. 2012;13:1396-406.

48. Shmelkov SV, Butler JM, Hooper AT, Hormigo A, Kushner J, Milde T, et al. CD133 expression is not restricted to stem cells, and both CD133 + and CD133- metastatic colon cancer cells initiate tumors. J Clin Invest. 2008;118:2111-20.

49. O'Brien CA, Kreso A, Jamieson CHM. Cancer stem cells and self-renewal. Clin Cancer Res. 2010;16:3113-20.

50. Hong X, Chedid K, Kalkanis SN. Glioblastoma cell line-derived spheres in serum-containing medium versus serum-free medium: a comparison of cancer stem cell properties. Int J Oncol. 2012;41:1693-700.

51. Lee J, Kotliarova S, Kotliarov Y, Li A, Su Q, Donin NM, et al. Tumor stem cells derived from glioblastomas cultured in bFGF and EGF more closely mirror the phenotype and genotype of primary tumors than do serum-cultured cell lines. Cancer Cell. 2006;9:391-403.

52. Moitra K. Overcoming Multidrug Resistance in Cancer Stem Cells. Biomed Res Int. 2015;2015:635745.

53. Golebiewska A, Brons NHC, Bjerkvig R, Niclou SP. Critical appraisal of the side population assay in stem cell and cancer stem cell research. Cell Stem Cell. 2011:8:136-47.

54. Schinkel AH. P-Glycoprotein, a gatekeeper in the blood-brain barrier. Adv Drug Deliv Rev. 1999;36:179-94.

55. Segal MB. The choroid plexuses and the barriers between the blood and the cerebrospinal fluid. Cell Mol Neurobiol. 2000;20:183-96.

56. Sarkaria JN, Hu LS, Parney IF, Pafundi DH, Brinkmann DH, Laack NN, et al, Is the blood-brain barrier really disrupted in all glioblastomas? A critical assessment of existing clinical data. Neuro Oncol. 2018;20:184-91.

57. Broadley KW, Hunn MK, Farrand KJ, Price KM, Grasso C, Miller RJ, et al. Side population is not necessary or sufficient for a cancer stem cell phenotype in glioblastoma multiforme. Stem Cells. 2011;29:452-61.

58. Golebiewska A, Bougnaud S, Stieber D, Brons NHC, Vallar L, Hertel F, et al. Side population in human glioblastoma is non-tumorigenic and characterizes brain endothelial cells. Brain. 2013;136:1462-75.
59. Song X, Xie L, Wang X, Zeng Q, Chen TC, Wang W, et al. Temozolomideperillyl alcohol conjugate induced reactive oxygen species accumulation contributes to its cytotoxicity against non-small cell lung cancer. Sci Rep. 2016;6:22762.

60. Zhang WB, Wang Z, Shu F, Jin YH, Liu HY, Wang QJ, et al. Activation of AMP-activated protein kinase by temozolomide contributes to apoptosis in glioblastoma cells via p53 activation and mTORC1 inhibition. J Biol Chem. 2010;285:40461-71.

61. Gorrini C, Harris IS, MakTW. Modulation of oxidative stress as an anticancer strategy. Nat Rev Drug Discov. 2013;12:931-47.

62. Chen Y, Azad MB, Gibson SB. Superoxide is the major reactive oxygen species regulating autophagy. Cell Death Differ. 2009;16(7):1040-52.

63. Ushio-Fukai M, Nakamura Y. Reactive oxygen species and angiogenesis: NADPH oxidase as target for cancer therapy. Cancer Lett. 2008;266:37-52.

64. Weng MS, Chang JH, Hung WY, Yang YC, Chien MH. The interplay of reactive oxygen species and the epidermal growth factor receptor in tumor progression and drug resistance. J Exp Clin Cancer Res. 2018;37:61.

65. Bastien Jl, McNeill KA, Fine HA. Molecular characterizations of glioblastoma, targeted therapy, and clinical results to date. Cancer. 2015;121:502-16.

66. Baillie N, Carr AC, Peng S. The use of intravenous vitamin $C$ as a supportive therapy for a patient with glioblastoma multiforme. Antioxidants (Basel). 2018;7:115.

67. Deng J, Liu AD, Hou GQ, Zhang X, Ren K, Chen XZ, et al. N-acetylcysteine decreases malignant characteristics of glioblastoma cells by inhibiting Notch2 signaling. J Exp Clin Cancer Res. 2019;38:2.

68. Monticone M, Taherian R, Stigliani S, Carra E, Monteghirfo S, Longo L, et al. NAC, tiron and trolox impair survival of cell cultures containing glioblastoma tumorigenic initiating cells by inhibition of cell cycle progression. PLoS One. 2014;9:e90085.

69. Zhou S, Wang X, Tan Y, Qiu L, Fang H, Li W. Association between vitamin $C$ intake and glioma risk: evidence from a meta-analysis. Neuroepidemiology. 2015;44:39-44.

70. Gruosso T, Mieulet V, Cardon M, Bourachot B, Kieffer Y, Devun F, et al. Chronic oxidative stress promotes $\mathrm{H} 2 \mathrm{AX}$ protein degradation and enhances chemosensitivity in breast cancer patients. EMBO Mol Med. 2016;8:527-49.

71. Sukumari-Ramesh S, Prasad N, Alleyne CH, Vender JR. Dhandapani KM. Overexpression of Nrf2 attenuates carmustine-induced cytotoxicity in U87MG human glioma cells. BMC Cancer. 2015;15:118.

72. Zhou S, Ye W, Shao Q, Zhang M, Liang J. Nrf2 is a potential therapeutic target in radioresistance in human cancer. Crit Rev Oncol Hematol. 2013;88:706-15.

73. Chhunchha B, Fatma N, Bhargavan B, Kubo E, Kumar A, Singh DP. Specificity protein, Sp1-mediated increased expression of Prdx6 as a curcumin-induced antioxidant defense in lens epithelial cells against oxidative stress. Cell Death Dis. 2011;2:e234.

74. Ryu H, Lee J, Zaman K, Kubilis J, Ferrante RJ, Ross BD, et al. Sp1 and Sp3 are oxidative stress-inducible, antideath transcription factors in cortical neurons. J Neurosci. 2003;23:3597-606.

75. Chang KY, Hsu TI, Hsu CC, Tsai SY, Liu JJ, Chou SW, et al. Specificity protein 1-modulated superoxide dismutase 2 enhances temozolomide resistance in glioblastoma, which is independent of $\mathrm{O}(6)$-methylguanine-DNA methyltransferase. Redox Biol. 2017;13:655-64.

76. Quijano C, Trujillo M, Castro L, Trostchansky A. Interplay between oxidant species and energy metabolism. Redox Biol. 2016;8:28-42.

77. Nathan C. Specificity of a third kind: reactive oxygen and nitrogen intermediates in cell signaling. J Clin Invest. 2003;111:769-78.

78. Winterbourn CC. Reconciling the chemistry and biology of reactive oxygen species. Nat Chem Biol. 2008;4:278-86.

79. Gough DR, Cotter TG. Hydrogen peroxide: a Jekyll and Hyde signalling molecule. Cell Death Dis. 2011;2:e213.

80. Thews O, Lambert C, Kelleher DK, Biesalski HK, Vaupel P, Frank J. Impact of therapeutically induced reactive oxygen species and radical scavenging by alpha-tocopherol on tumor cell adhesion. Oncol Rep. 2007;18:965-71.

81. Trachootham D, Alexandre J, Huang P. Targeting cancer cells by ROSmediated mechanisms: a radical therapeutic approach? Nat Rev Drug Discov. 2009;8:579-91. 
82. Fukai T, Ushio-Fukai M. Superoxide dismutases: role in redox signaling, vascular function, and diseases. Antioxid Redox Signal. 2011;15:1583-606.

83. Hsieh CH, Lin YJ, Wu CP, Lee HT, Shyu WC, Wang CC. Livin contributes to tumor hypoxia-induced resistance to cytotoxic therapies in glioblastoma multiforme. Clin Cancer Res. 2015;21:460-70.

84. Heffernan JM, Sirianni RW. Modeling microenvironmental regulation of glioblastoma stem cells: a biomaterials perspective. Front Mater. 2018:5:7.

85. Jamal M, Rath BH, Williams ES, Camphausen K, Tofilon PJ. Microenvironmental regulation of glioblastoma radioresponse. Clin Cancer Res. 2010;16:6049-59.

86. Gilbertson RJ, Rich JN. Making a tumour's bed: glioblastoma stem cells and the vascular niche. Nat Rev Cancer. 2007;7:733-6.

87. Vieira HLA, Alves PM, Vercelli A. Modulation of neuronal stem cell differentiation by hypoxia and reactive oxygen species. Prog Neurobiol. 2011;93:444-55.

88. Kolenda J, Jensen SS, Aaberg-Jessen C, Christensen K, Andersen C Brünner $\mathrm{N}$, et al. Effects of hypoxia on expression of a panel of stem cell and chemoresistance markers in glioblastoma-derived spheroids. J Neurooncol. 2011;103:43-58.

89. Persano L, Pistollato F, Rampazzo E, Puppa AD, Abbadi S, Frasson C, et al. BMP2 sensitizes glioblastoma stem-like cells to temozolomide by affecting HIF-1alpha stability and MGMT expression. Cell Death Dis. 2012;3:e412.

90. Pistollato F, Abbadi S, Rampazzo E, Persano L, Della Puppa A, Frasson C, et al. Intratumoral hypoxic gradient drives stem cells distribution and MGMT expression in glioblastoma. Stem Cells. 2010;28:851-62.

91. Gargiulo G, Cesaroni M, Serresi M, de Vries N, Hulsman D, Bruggeman SW, et al. In vivo RNAi screen for BMI1 targets identifies TGF-beta/BMPER stress pathways as key regulators of neural- and malignant gliomastem cell homeostasis. Cancer Cell. 2013;23:660-76.

92. Facchino S, Abdouh M, Chatoo W, Bernier G. BMI1 confers radioresistance to normal and cancerous neural stem cells through recruitment of the DNA damage response machinery. J Neurosci. 2010;30:10096-111.

93. Garnier D, Meehan B, Kislinger T, Daniel P, Sinha A, Abdulkarim B, et al. Divergent evolution of temozolomide resistance in glioblastoma stem cells is reflected in extracellular vesicles and coupled with radiosensitization. Neuro Oncol. 2018;20:236-48.

94. Chen $\mathrm{H}$, Chan DC. Mitochondrial dynamics in regulating the unique phenotypes of cancer and stem cells. Cell Metab. 2017;26:39-48.

95. Caino MC, Altieri DC. Molecular pathways: mitochondrial reprogramming in tumor progression and therapy. Clin Cancer Res. 2016;22:540-5.

96. Guerra F, Arbini AA, Moro L. Mitochondria and cancer chemoresistance. Biochim Biophys Acta Bioenerg. 2017;1858:686-99.

97. Filippi MD, Ghaffari S. Mitochondria in the maintenance of hematopoietic stem cells: new perspectives and opportunities. Blood. 2019;133:1943-52.

98. Oliva CR, Nozell SE, Diers A, McClugage SG, Sarkaria JN, Markert JM, et al. Acquisition of temozolomide chemoresistance in gliomas leads to remodeling of mitochondrial electron transport chain. J Biol Chem. 2010;285:39759-67.

99. Strickland M, Stoll EA. Metabolic reprogramming in glioma. Front Cell Dev Biol. 2017;5:43.

100. Pavlova NN, Thompson CB. The emerging hallmarks of cancer metabolism. Cell Metab. 2016;23:27-47.

101. Doherty JR, Cleveland JL. Targeting lactate metabolism for cancer therapeutics. J Clin Invest. 2013;123:3685-92.

102. Zhang J, Nuebel E, Daley GQ, Koehler CM, Teitell MA. Metabolic regulation in pluripotent stem cells during reprogramming and self-renewal. Cell Stem Cell. 2012;11:589-95.

103. Moussaieff A, Rouleau M, Kitsberg D, Cohen M, Levy G, Barasch D, et al. Glycolysis-mediated changes in acetyl-CoA and histone acetylation control the early differentiation of embryonic stem cells. Cell Metab. 2015;21:392-402.

104. Chang CW, Chen YS, Chou SH, Han CL, Chen YJ, Yang CC, et al. Distinct subpopulations of head and neck cancer cells with different levels of intracellular reactive oxygen species exhibit diverse stemness, proliferation, and chemosensitivity. Cancer Res. 2014;74:6291-305.
105. Chien CH, Chuang JY, Yang ST, Yang WB, Chen PY, Hsu TI, et al. Enrichment of superoxide dismutase 2 in glioblastoma confers to acquisition of temozolomide resistance that is associated with tumor-initiating cell subsets. J Biomed Sci. 2019;26:77.

106. Mei X, Chen YS, Chen FR, Xi SY, Chen ZP. Glioblastoma stem cell differentiation into endothelial cells evidenced through live-cell imaging. Neuro Oncol. 2017;19:1109-18.

107. Yang H, Villani RM, Wang H, Simpson MJ, Roberts MS, Tang M, et al. The role of cellular reactive oxygen species in cancer chemotherapy. J Exp Clin Cancer Res. 2018;37:266.

108. Mohrenz IV, Antonietti P, Pusch S, Capper D, Balss J, Voigt S, et al. Isocitrate dehydrogenase 1 mutant $\mathrm{R} 132 \mathrm{H}$ sensitizes glioma cells to BCNUinduced oxidative stress and cell death. Apoptosis. 2013;18:1416-25.

109. Hottinger AF, Pacheco P, Stupp R. Tumor treating fields: a novel treatment modality and its use in brain tumors. Neuro Oncol. 2016;18:1338-49.

110. Jo Y, Kim EH, Sai S, Kim JS, Cho JM, Kim H, et al. Functional biological activity of sorafenib as a tumor-treating field sensitizer for glioblastoma therapy. Int J Mol Sci. 2018;19.

111. Singer E, Judkins J, Salomonis N, Matlaf L, Soteropoulos P, McAllister $\mathrm{S}$, et al. Reactive oxygen species-mediated therapeutic response and resistance in glioblastoma. Cell Death Dis. 2015;6:e1601.

112. Zhu Z, Du S, Du Y, Ren J, Ying G, Yan Z. Glutathione reductase mediates drug resistance in glioblastoma cells by regulating redox homeostasis. J Neurochem. 2018;144:93-104.

113. Su YT, Chen $R$, Wang H, Song H, Zhang Q, Chen LY, et al. Novel targeting of transcription and metabolism in glioblastoma. Clin Cancer Res. 2018;24:1124-37.

114. Chen N, Wu L, Yuan H, Wang J. ROS/autophagy/Nrf2 pathway mediated low-dose radiation induced radio-resistance in human lung adenocarcinoma A549 cell. Int J Biol Sci. 2015;11:833-44.

115. Desantis V, Saltarella I, Lamanuzzi A, Mariggiò MA, Racanelli V, Vacca A, et al. Autophagy: a new mechanism of prosurvival and drug resistance in multiple myeloma. Transl Oncol. 2018;11:1350-7.

116. Filomeni G, De Zio D, Cecconi F. Oxidative stress and autophagy: the clash between damage and metabolic needs. Cell Death Differ. 2015;22:377-88.

117. Zeng W, Xiao T, Cai A, Cai W, Liu H, Liu J, et al. Inhibiting ROS-TFEBdependent autophagy enhances salidroside-induced apoptosis in human chondrosarcoma cells. Cell Physiol Biochem. 2017:43:1487-502.

118. Vessoni AT, Quinet A, de Andrade-Lima LC, Martins DJ, Garcia CCM, Rocha CRR, et al. Chloroquine-induced glioma cells death is associated with mitochondrial membrane potential loss, but not oxidative stress. Free Radic Biol Med. 2016;90:91-100.

119. Wang H, Zhao Z, Lei S, Martins DJ, Garcia CCM, Rocha CRR, et al. Gambogic acid induces autophagy and combines synergistically with chloroquine to suppress pancreatic cancer by increasing the accumulation of reactive oxygen species. Cancer Cell Int. 2019;19:7.

120. Lee J, Giordano S, Zhang J. Autophagy, mitochondria and oxidative stress: cross-talk and redox signalling. Biochem J. 2012;441:523-40.

121. Lohitesh K, Saini H, Srivastava A, Mukherjee S, Roy A, Chowdhury R. Autophagy inhibition potentiates SAHA-mediated apoptosis in glioblastoma cells by accumulation of damaged mitochondria. Oncol Rep. 2018:39:2787-96.

122. Avgustinova A, Benitah SA. The epigenetics of tumour initiation: cancer stem cells and their chromatin. Curr Opin Genet Dev. 2016;36:8-15.

123. Saygin C, Matei D, Majeti R, Reizes O, Lathia JD. Targeting cancer stemness in the clinic: from hype to hope. Cell Stem Cell. 2019;24:25-40.

124. Hsu CC, Chang WC, Hsu TI, Liu JJ, Yeh SH, Wang JY, et al. Suberoylanilide hydroxamic acid represses glioma stem-like cells. J Biomed Sci. 2016;23:81.

\section{Publisher's note}

Springer Nature remains neutral with regard to jurisdictional claims in published maps and institutional affiliations. 